\title{
Acute Stress Symptoms in Families of Patients Admitted to the Intensive Care Unit during the First 24 Hours Following Admission in Japan
}

\author{
Miyuki Komachi', Kiyoko Kamibeppu ${ }^{2}$ \\ ${ }^{1}$ Department of Nurse Practitioner Training, Division of Healthcare, Graduate School of Medical Welfare, \\ International University of Health and Welfare, Tokyo, Japan \\ ${ }^{2}$ Department of Family Nursing, Division of Health Sciences \& Nursing, Graduate School of Medicine, University \\ of Tokyo, Tokyo, Japan \\ Email: mhasegawa-tky@umin.ac.jp
}

Received 16 March 2015; accepted 30 March 2015; published 2 April 2015

Copyright (c) 2015 by authors and Scientific Research Publishing Inc.

This work is licensed under the Creative Commons Attribution International License (CC BY). http://creativecommons.org/licenses/by/4.0/

c) (i) Open Access

\begin{abstract}
Families of patients in the intensive care unit often experience sever stress. Understanding their experience is important for providing family-centered care during this difficult period. Little is known about the experience of families of patients admitted to the intensive care unit (ICU). To evaluate the prevalence and factors associated with acute stress symptoms among families of patients admitted to the ICU, we carried out a cross-sectional study at a teaching and advanced treatment hospital. The mean total Impact of Event Scale-Revised (IES-R) score differed significantly between planned and unplanned ICU admissions $(t=4.03, p<0.05)$, indicating a main effect of admission type $(F=18.5, p<0.05)$. There was no significant main effect of relationship $(F=0.05$, $p=0.82)$ or interaction effect of admission type and relationship $(F=0.54, p=0.47)$. Multiple regression analysis indicated that admission type was significantly associated with acute stress symptoms $(B=18.09, \beta=0.47, p<0.01)$, and explained $22 \%$ of the variance in total IES-R score. Whether a patient had a planned or unplanned admission to the ICU influenced symptoms associated with acute stress symptoms of family members more than did getting support from nurses, being the patient's spouse, or the severity of illness of the patient.
\end{abstract}

\section{Keywords}

Intensive Care Unit, Families, within 24 Hours, Acute Stress Symptoms, Post-Traumatic Stress Disorder 


\section{Introduction}

Patients admitted to the intensive care unit (ICU) may not be able to communicate for several reasons such as sedation, ventilator use, delirium, or coma [1]. According to a survey of healthcare facilities and a bedside overview in Japan, from 2002 to 2005 the number of operations performed on patients increased, and from 2008 to 2011 the number of ICU beds increased [2] [3]. Families of patients in the ICU experience severe stress, as they often have to make decisions on behalf of the patient when the risk to the patient's life is high [4] [5]. Family members need to listen to healthcare providers' explanations about therapeutic options and the patient's prognosis to act as proxy decision-makers for the patient. Some family members may also experience mental shock after seeing the condition of a loved one in the ICU, such as covered in blood and/or connected to medical apparatuses, especially when comparing the patient's current condition to before the ICU admission [6]. Recent studies show that experiencing severe mental stress during the initial period after a patient's admission to the ICU may be one of the most influencing predictive factors for development of post-traumatic stress disorder (PTSD) in family members [7] [8]. However, little is known about the early experience of families of patients admitted to the ICU. It is important to understand this experience and evaluate the mental health of family members of patients in the ICU to help provide family-centered care [1].

Previous quantitative research in Brazil, Europe, the United States, and China, found that family members experience symptoms related to PTSD from 24 hours after ICU admission until ICU discharge 90 days later [9]-[11]. At 30 and 90 days after ICU discharge following an average length of stay of 5 days, $2.5 \%$ and $4.9 \%$, respectively, of family members suffered from PTSD symptoms [9]. Sundararajan et al. reported that $41.3 \%$ of family members had PTSD symptoms (IES-R score > 26) after 48 hours of ICU admission (average length of stay of 7 days) [10]. McAdam et al. investigated 41 families and reported that $42 \%$ of families had symptoms of PTSD during ICU admission [11]. Gries et al. surveyed 226 families after ICU death or within 30 hours after ICU discharge (average length of stay of 3.5 days) and reported that $14 \%$ of families had symptoms related to PTSD [12]. Results of a study of 133 families reported that $71 \%$ of family members experienced symptoms of severe PTSD and 29\% experienced moderate symptoms related to PTSD from after 24 hours of ICU admission up to 14 days later [13].

Although previous studies examined symptoms related to PTSD in family members of patients admitted to the ICU, to our knowledge, no studies have examined acute stress symptoms in family members of ICU admitted patients within 24 hours of ICU admission.

Based on previous studies, we identified the importance of four factors: admission type (planned or unplanned) [12] [13], family relationship [6] [14], severity of the patient’s illness [15]-[17], and social support [18]-[21].

\section{Aim}

The study were (1) to investigate the prevalence of acute stress symptoms; and (2) to examine factors related to acute stress symptoms in these family members during this early time following a patient's ICU admission.

\section{Methods}

\subsection{Design}

This was a cross-sectional study.

\subsection{Setting and Participants}

This study was performed at a teaching and advanced treatment hospital. This facility has a medical and surgical ICU within the hospital, in addition to an emergency ICU in the medical emergency center. We conducted the survey and collected pertinent medical records in the medical/surgical ICU (8 beds) and the emergency ICUs (8 beds, 4 in the Coronary Care Unit and 4 in the emergency ICU).

Inclusion criteria for patients were (1) planned admission to the ICU after surgery; (2) unplanned immediate admission to the ICU for a flare-up of their condition in the general ward; and (3) unplanned admission to the ICU after treatment in an emergency room. Exclusion criteria for patients included the following: (1) the patient lived alone; and (2) the patient was admitted to the ICU due to a psychiatric disorder. Inclusion criteria for family members included the following: (1) a person having a significant relationship with the patient, such as a 
spouse, child, parent, sibling, or relative; (2) granted permission to be surveyed by a physician and a nurse; (3) older than 20 years; (4) able to provide informed consent; and (5) able to communicate in Japanese. Exclusion criteria for family members included (1) being under treatment for a mental or physical disease; and (2) being a caregiver for other family members.

We recruited from November 2010 to March 2011 and collected data from electronic medical records through April 2011.

We obtained prior consent from physicians, managing nurses, and nursing staff assigned to patients admitted to the medical/surgical ICUs within the hospital and medical emergency center to gain a list of potential participants. We fully explained our research and asked for a list of participants who satisfied the inclusion criteria for patients and families and visited the family member in medical/surgical ICUs within 24 hours. We requested that participants return the questionnaire by mail to avoid placing pressure on them to complete the information in front of us and to protect the participant's anonymity. We asked participants to fill out questionnaires within 24 hours of a family member's admission to the ICU.

\subsection{Data Collection}

We created a questionnaire consisting of survey items from PTSD studies [11] [22] [23]. The questionnaire asked the following: demographics of the family (age, sex, size of household, education level, marital status, family relationship to patient, and household income); participant's history of mental disorders; family members' history of mental disorders; experience with loss of a family member; experience with loss of relative; occurrence of a recent stressful event; and history of traumatic stress. For this latter variable, we used an event checklist that was published in the Clinician-Administered PTSD Scale for DSM-IV [24]. Electronic medical records were used to collect the following information: demographics of the patient (age and sex); clinical characteristics of the patient (Acute Physiology and Chronic Health Evaluation [APACHE] II score, worse score of patient within 24 hours) [25]; length of ICU stay; reason for admission to ICU; period over which mechanical ventilation was used; patient treatment factors (i.e., use of vasopressors, cardiac stimulants, sedatives, blood transfusions, mechanical ventilator support, an artificial heart lung machine, or hemodialysis); presence of complications; number who died during ICU stay; history of ICU admissions; and ICU admission type.

We adopted the Japanese version of the Impact of Event Scale-Revised (IES-R-J: hereafter referred to as IES-R in this study) from Asukai to measure acute stress symptoms in the family members of patients admitted to the ICU within 24 hours [26] [27]. The IES-R has been tested in various studies, including the survey of the Great Hanshin-Awaji Earthquake, and accepted as a reliable and valid scale for measurement of symptoms related to PTSD among Japanese subjects [26]. The IES-R items in the study comprised three dimensions (eight intrusion items, eight avoidance items, and six hyperarousal items) described in the DSM-IV-TR to categorize acute stress symptoms [28]. It consisted of 22 statements that the responder rated on a 5-point scale (0 to 4) in terms of response to a specific stressful life event in the past week. Every acute stress symptom score and the total score on the IES-R were measured. A higher score indicates a higher level of acute stress symptoms. This study used the IES-R score of 25 as a cutoff to represent high risk of Acute Stress Disorder (ASD) in order to make comparisons with previous studies [26]. Cronbach's coefficient alpha of the Japanese version of the IES-R is 0.94 . Cronbach's coefficient alpha of IES-R in our study was 0.96 . Cronbach's coefficient alpha values of the three IES-R subscales of intrusion, avoidance, and hyperarousal, were $0.94,0.76$, and 0.87 , respectively.

The Social Support Questionnaire (SSQ) was developed by Sarason et al. as a reliable, valid, and convenient index of social support [29]. Both the 27-item version and an abbreviated 6-item version have been shown to have high internal consistency, test-retest reliability, and validity [29]. We used the 6-item instrument developed by Furukawa et al. [30] to measure satisfaction with social support. The SSQ inquires about the number of people in the respondent's support network and satisfaction with the network. The satisfaction score is measured on a 6-point Likert-type scale (i.e., "very dissatisfied = 0" to "very satisfied = 5"). The internal consistency values in our sample were 0.94 and 0.94 for the number score and satisfaction score, respectively. Cronbach's coefficient alpha was 0.87 for the number score and 0.94 for the satisfaction score.

\subsection{Statistical Analysis}

We used the t-test to compare the mean IES-R values between planned and unplanned admissions. We used two-way analysis of variance (ANOVA) to examine the main effect and interaction in each relationship (spouse/ 
other family member) and ICU admission (unplanned/planned) on IES-R score. We conducted multiple linear regression analysis using the compulsive injection method to explain factors affecting acute stress symptoms. We selected the total IES-R score as the dependent variable. Critical demographic data (e.g., age and sex) and factors associated with acute stress symptoms (ICU admission type, family relationship, APACHE II score, and SSQ satisfaction) were independent variables. We divided age, APACHE II score, and SSQ satisfaction into binary variables. We divided participants' age into $\geq 60$ years and $\leq 59$ years because 60 is the general age of retirement in Japan. We divided the APACHE II scores into median values ( $\geq 15$ points and $\leq 14$ points). We divided the SSQ satisfaction score into 0 and $\geq 1$, because 0 is the most frequent value ( $\mathrm{n}=10,13.7 \%$ ). Regarding relationships, we used binary variables "spouse and partner" and "other family member". ICU admission type was divided into unplanned and planned admissions. We used the t-test for independent variables to evaluate the dependent variable and independent variables before performing multi-regression analysis. We verified variance inflation factor to consider multicollinearity [31]. Statistical significance was set at $\mathrm{p}<0.05$. All statistical analyses were carried out using SPSS 17.0 (SPSS, Chicago, IL, USA).

\subsection{Ethical Considerations}

This study was approved by the ethics committees of both the researchers' academic medical centers and the academic medical center at which the research was conducted. Participants received written and oral explanations of the aim of the study, including assurances that the patient's condition and schedule would take first priority; that participation was voluntary and would not impact the patient's care; that consent could be withdrawn at any time; and that information would be kept anonymous. All participants provided written informed consent, though we did not obtain consent from the patients.

\subsection{Validity and Reliability}

To examine content validity, we modified the survey items based on the opinions of a psychological researcher, nursing researcher, physicians who treated the illness of ICU admitted patients, medical/surgical ICU nurses, and emergency ICU nurses. We asked five nurses who had worked in clinical practice for more than 3 years to take a pretest to assess whether they could understand the content of the questionnaire.

\section{Results}

Of the 60 families who returned the questionnaires, 54 participants reported encountering a traumatic event (82.2\% prevalence of traumatic events among respondents), which resulted in 54 responses in total (total response rate was $74.0 \%$; response rate in planned ICU admission was $80.0 \%$; response rate in unplanned ICU admission was 66.7\%) (Figure 1(a)).

Table 1 and Table 2 show the demographics and clinical characteristics of patients and their accompanying family members and patients' primary causative diseases for ICU admission, respectively. The ratios of family members whose IES-R scores that were above 25 were 29.6\% (16 of 54) of total participants, 21.9\% (7 of 32) of planned admission participants and $50.0 \%$ (11 of 22) of unplanned participants.

Table 3 shows findings regarding major factors related to acute stress symptoms using the IES-R. Mean total IES-R scores in planned and unplanned ICU admissions differed significantly $(\mathrm{t}=4.03, \mathrm{p}<0.05)$.

Table 4 shows mean scores (standard deviation) and median (range) of sex, age, relationship, APACHE II score, and SSQ satisfaction scores. For multiple regression analysis, the selected factors were used as independent variables and IES-R total score as the dependent variable. Admission type was significantly associated with acute stress disorder $(\mathrm{B}=18.09, \beta=0.47, \mathrm{p}<0.01)$. For the acute stress symptoms, results of multiple regression analysis indicated that the variable explained the $22 \%$ variance in total IES-R score. Neither APACHE II score nor SSQ satisfaction related to acute stress symptoms (Table 4).

\section{Discussion}

Our findings suggest that the longer a family stays at the ICU, the greater the severity of the family's suffering from traumatic stress. For instance, the prevalence of high risk of ASD in this study was $29.6 \%$ (IES-R score > 25; APACHE II mean score $=17.2$; ICU stay $<24 \mathrm{~h}$ ), whereas the previously-reported prevalence of high risk of PTSD for close relatives of ICU patients (ICU stay > 48 h) was $41.2 \%$ (IES-R score > 26; APACHE II mean 


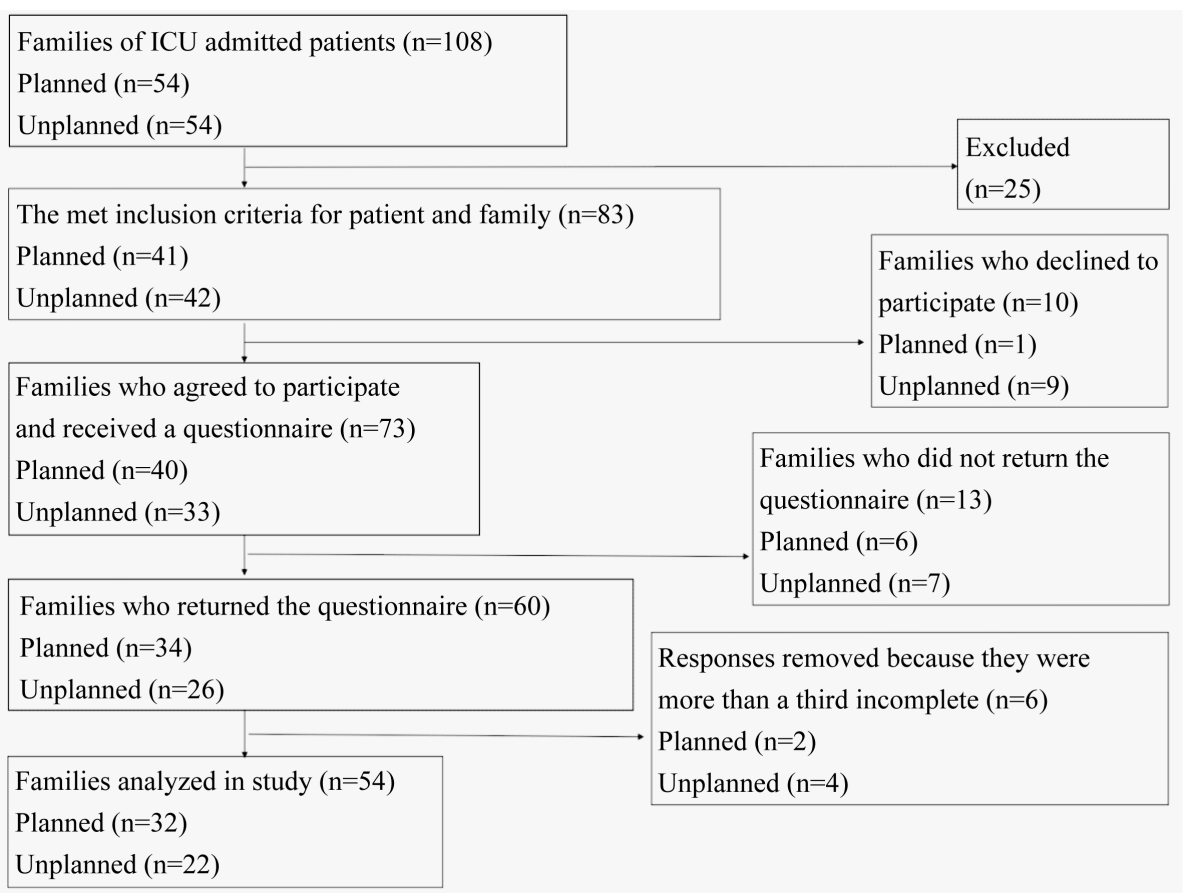

(a)

\begin{tabular}{lcc}
\hline & Planned $(\mathrm{n}=13)$ & Unplanned $(\mathrm{n}=12)$ \\
\hline $\begin{array}{l}\text { Reasons for exclusion of family members } \\
\text { Caring for other family members }\end{array}$ & 3 & 2 \\
Reasons for exclusion of patients & 6 & 7 \\
Over 24 hours of admission & 1 & 1 \\
Living alone & 0 & 2 \\
ICU admission resulting from a psychiatric disorder & 3 & 0 \\
Not admitted to ICU after surgery & & \\
\hline
\end{tabular}

(b)

Figure 1. Enrollment of study participants. (a) This chart begins with the 108 families of patients admitted to the ICU, both planned and unplanned, and illustrates the number of families who were excluded from the final analysis for not meeting inclusion criteria, declining to participate, not returning the questionnaire, or leaving more than one third of the questionnaire incomplete. (b) The reasons 25 families and patients did not meet the inclusion criteria are categorized and divided into planned and unplanned ICU admissions. ICU: intensive care unit.

score $=19.9)$ [10]. Even though the mean scores of the patient's disease severity were similar, traumatic stress of the family was more severe with prolonged time in the ICU. Also, one mean IES-R score of this study (APACHE II score > 20; received mechanical ventilation) was 27.8, while the previously-reported score pertaining to the same level of patient's disease severity but after a longer stay (APACHE II score $>20$; received mechanical ventilation; ICU stay $>72 \mathrm{~h}$ ) was 35.2 [11]. This suggests that there is a need for offering the support to family members as early as possible during the ICU stay in order to reduce traumatic stress.

The current results showed that unplanned admissions are the most stressful event for family members. These results support the findings of Mitchell et al. (2004), who demonstrated that family members of patients who were transferred from the ICU to a general ward (i.e., unplanned admissions) were at high risk of developing negative psychological symptoms [21]. Previous studies in France, the United States, and China showed that when ICU admission occurs unexpectedly, the family experiences psychiatric shock [12] [13] [19]. 
Table 1. Characteristics of family members $(n=54)$ and patients admitted to the ICU $(n=54)$.

\begin{tabular}{|c|c|c|c|c|c|}
\hline & n (\%) & Mean & SD & Median & Range \\
\hline \multicolumn{6}{|l|}{ Family member characteristics } \\
\hline Age & & 53.3 & 12.4 & 54.0 & $28-79$ \\
\hline Number who lived with the patient in the ICU & & 3.0 & 1.1 & 3.0 & $1-7$ \\
\hline Sex (female) & $34(63.0)$ & & & & \\
\hline Education level (high school or higher) & $46(85.2)$ & & & & \\
\hline Marital status (married) & $42(77.8)$ & & & & \\
\hline \multicolumn{6}{|l|}{ Relationship to patient } \\
\hline Spouse & $26(48.1)$ & & & & \\
\hline Child & $15(27.8)$ & & & & \\
\hline Parent & $4(7.4)$ & & & & \\
\hline Sibling & $8(14.8)$ & & & & \\
\hline Other & $1(1.9)$ & & & & \\
\hline \multicolumn{6}{|l|}{ Household income } \\
\hline$<3$ million yen & $18(33.3)$ & & & & \\
\hline 3 million - 10 million yen & $30(55.5)$ & & & & \\
\hline$>10$ million yen & $4(7.3)$ & & & & \\
\hline Unknown & $2(3.7)$ & & & & \\
\hline History of mental disorder & $2(3.7)$ & & & & \\
\hline Family has a member with a history of mental illness & $1(1.9)$ & & & & \\
\hline Experienced loss of a family member & $43(79.6)$ & & & & \\
\hline Experienced loss of a relative & $37(68.5)$ & & & & \\
\hline Experienced a stressful event within the past month & $14(25.9)$ & & & & \\
\hline Encountered a traumatic event in the past & $4(7.4)$ & & & & \\
\hline \multicolumn{6}{|l|}{ Patient characteristics } \\
\hline Age & & 65.6 & 13.2 & 67.5 & $28-86$ \\
\hline APACHE II score & & 17.2 & 8.7 & 17.5 & $1-40$ \\
\hline Length of ICU stay (hours) & & 86.8 & 97.2 & 42.9 & $12-491$ \\
\hline Mechanically ventilated period (hours) & & 59.1 & 76.6 & 37.5 & $3-360$ \\
\hline Sex (female) & $16(29.6)$ & & & & \\
\hline Use of heart stimulant and vasopressors & $25(46.3)$ & & & & \\
\hline Use of sedation & $23(42.6)$ & & & & \\
\hline Use of ventilation & 29 (53.7) & & & & \\
\hline Use of heart - lung machine & $4(7.0)$ & & & & \\
\hline Use of blood transfusion & $17(31.5)$ & & & & \\
\hline Use of hemodialysis & $2(4.0)$ & & & & \\
\hline Number with complications & $25(46.3)$ & & & & \\
\hline Number who died during ICU stay & $3(5.6)$ & & & & \\
\hline Patient was admitted to ICU in the past & $12(22.2)$ & & & & \\
\hline Planned admission & 32 (59.3) & & & & \\
\hline
\end{tabular}

APACHE II score, Acute Physiology and Chronic Health Evaluation II score; ICU, intensive care unit; SD, standard deviation. 
Table 2. Primary causative diseases for ICU admission by type of admission $(n=54)$.

\section{Primary causative diseases for ICU admission by type of admission}

Hepato-biliary-pancreatic cancers

Esophageal cancer or other alimentary canal cancer

Lung cancer

Other underlying causes of cancer

Cancer recurrence

Acute ischemic heart disease

Valvular heart disease

Arterial disease and peripheral arterial occlusive disease

Heart failure

Irregular heartbeat

Septic shock

Hemorrhagic shock

High-energy trauma injuries

Cardiac arrest cause by respiratory failure

Other

Total

ICU: intensive care unit.
Planned

\section{2}

3

6

2

2

3

5

7

0

0

0

0

0

0

2

32

\section{Unplanned}

0

0

0

0

0

7

0

2

5

1

3

2

1

1

0

22

Table 3. Impact of Event Scale-Revised scores for major factors associated with acute stress disorder in family members of patients admitted to the ICU.

\begin{tabular}{|c|c|c|c|c|c|c|c|c|c|c|c|}
\hline & & \multicolumn{5}{|c|}{ Planned Admission } & \multicolumn{5}{|c|}{ Unplanned Admission } \\
\hline & & $\mathrm{n}$ & Mean & $\mathrm{SD}$ & Median & Range & $\mathrm{n}$ & Mean & $\mathrm{SD}$ & Median & Range \\
\hline Total & & 32 & 9.9 & 12.4 & 5.5 & $0-51$ & 22 & 29.6 & 20.5 & 25.0 & $2-65$ \\
\hline \multirow[t]{2}{*}{ Sex } & Male & 11 & 3.8 & 3.4 & 4.0 & $0-10$ & 7 & 30.0 & 17.7 & 26.0 & $6-61$ \\
\hline & Female & 21 & 13.1 & 13.1 & 8.0 & $1-51$ & 15 & 29.3 & 22.2 & 24.0 & $2-65$ \\
\hline \multirow[t]{2}{*}{ Age } & $<60$ years & 23 & 10.3 & 10.3 & 5.0 & $0-51$ & 18 & 31.4 & 21.3 & 26.5 & $2-65$ \\
\hline & $\geq 60$ years & 9 & 8.9 & 8.9 & 6.0 & $0-31$ & 4 & 21.0 & 15.6 & 15.0 & $10-44$ \\
\hline \multirow[t]{2}{*}{ Relationship } & Spouse & 16 & 12.1 & 14.5 & 6.0 & $0-51$ & 10 & 28.3 & 21.7 & 25.5 & $2-64$ \\
\hline & Other family member & 16 & 7.7 & 10.0 & 5.0 & $0-43$ & 12 & 30.6 & 20.3 & 24.5 & $6-65$ \\
\hline \multirow[t]{2}{*}{ APACHE II score } & $<15$ & 18 & 5.9 & 4.6 & 5.5 & $0-17$ & 6 & 42.0 & 21.2 & 40.0 & $17-65$ \\
\hline & $\geq 15$ & 14 & 15.0 & 17.1 & 5.5 & $0-51$ & 16 & 24.9 & 18.8 & 22.0 & $2-61$ \\
\hline \multirow[t]{2}{*}{ SSQ satisfaction } & 0 & 5 & 4.2 & 4.6 & 3.0 & $0-12$ & 4 & 43.5 & 25.3 & 53.5 & $6-61$ \\
\hline & $\geq 1$ & 25 & 11.4 & 13.6 & 8.0 & $0-51$ & 17 & 27.2 & 18.9 & 24.0 & $2-65$ \\
\hline
\end{tabular}

Note: values were missing from some participants. APACHE II score, Acute Physiology and Chronic Health Evaluation II score; ICU, intensive care unit; SSQ, Social Support Questionnaire. 
Table 4. Multiple regression analysis of major factors associated with acute stress disorder in family members of patients admitted to the ICU $(n=54)$.

\begin{tabular}{|c|c|c|c|c|}
\hline & B & $\beta$ & $\mathbf{t}$ & $\mathbf{p}$ \\
\hline $\operatorname{Sex}^{\mathrm{a}}$ & -5.23 & -0.13 & -0.89 & 0.38 \\
\hline Age $^{b}$ & -2.69 & -0.56 & -0.44 & 0.66 \\
\hline Relationship $^{c}$ & 0.70 & 0.02 & 0.13 & 0.90 \\
\hline Admission type $^{\mathrm{d}}$ & 18.09 & 0.47 & 3.46 & $<0.01$ \\
\hline APACHE II score ${ }^{\mathrm{e}}$ & 5.60 & 0.14 & 1.04 & 0.31 \\
\hline SSQ satisfaction ${ }^{\mathrm{f}}$ & -5.62 & -0.11 & -0.85 & 0.40 \\
\hline $\mathrm{R} 2$ & 0.32 & & & \\
\hline Adjusted R2 & $0.22^{\dagger}$ & & & \\
\hline
\end{tabular}

Greater disease severity of patients admitted to the ICU was not related to acute stress symptoms in the family. The results support the finding of Balluffi et al. (2004), who examined the relationship between ASD in parents of infants and children admitted to the pediatric intensive care unit (PICU) [32]. The means of APACHE II scores of unplanned and planned admission in this study were 20.4 and 14.6, respectively. Thus, the disease severity of patients with unplanned admissions was higher than that of patients with planned admissions. However, this did not impact the family's experience of acute stress symptoms. This finding differs from reports that showed that severity of the patient admitted to the ICU affected the psychiatric stress of the family [19] [33].

There was no significant association between family members' low satisfaction with social support and factors related to acute stress symptoms. One study showed that the more support a person perceives having, the lower their psychiatric stress, which leads to an improved health state [34]. Other studies have shown that the perception of having a social support system eases symptoms related to PTSD [18] [20]. Munakata et al. reported that persons are able to relieve stress reactions by perceiving that they have a strong social support network as well as the ability to use this network [35]. However, it may be difficult for family members of patients admitted to the ICU to perceive and use their social support network, because they may be too upset about the patient. Nakai et al. conducted a qualitative study about subjective aspects of mothers of children with birth defects, and found that it is necessary to facilitate access to the social support system [36]. When healthcare professionals provide social support to a family member of a patient who has just been admitted to the ICU, it is important for them to consider the possibility that the family is confused about the situation and to provide guidance for them to tap into their support system.

This study has several limitations. First, this study was directed at the families of patients who were transferred to the medical/surgical ICU within a hospital and emergency ICU admission center in a teaching and advanced treatment hospital. This could introduce selection bias regarding the state of the family. The findings of this study may not apply to families of patients admitted to the ICU who were transferred from a different hospital. Second, we need to study consecutively admitted recruits, increase the number of eligible persons, collect data on each admission type, and address the differences in characteristics of the family and patients that could be attributed to our methods of data collection. The study was conducted at a teaching and advanced treatment hospital in which experienced healthcare professionals provide high-quality medical care to severely ill patients and their families. As the patients and their families came to this hospital based on its reputation for high-quality care, ICU admitted patients were more seriously ill; this may have been a source of possible bias. Third, the questionnaire of this study was a Japanese self-administered questionnaire, which means that findings might be underestimated or overestimated. Fourth, this study used a questionnaire that evaluates acute stress symptoms. Participants were asked to fill out the questionnaire right after their family member was admitted to the ICU. However, the possibility of recall bias cannot be ruled out, especially as family members were under a great deal 
of stress when completing the questionnaire. Fifth, this study was not able to evaluate ASD since it did not involve any diagnostic interview. Sixth, the changes regarding PTSD diagnosis recently proposed in the DSM-V were not taken into account [37]. The fact that the DSM-V expands the DSM-IR-TR's three symptom clusters to four symptom clusters needs to be considered when interpreting the results of this study.

\section{Conclusion}

Our results showed a difference in acute stress symptoms in family members within 24 hours of a loved one being admitted to the ICU with regard to admission type. It was clear that acute stress symptoms in families of patients with unplanned ICU admissions were more severe than in families of patients with planned ICU admissions, and, by multiple regression analysis, ICU admission type had a major influence on acute stress symptoms.

\section{Acknowledgements}

We gratefully acknowledge the help and cooperation of Kazuko Kitahara, RN, the former director of nursing at Fukushima Medical University Hospital, and Kiyomi Onda, RN, MS.

\section{References}

[1] McAdam, J.L. and Puntillo, K. (2009) Symptoms Experienced by Family Members of Patients in Intensive Care Units. American Journal of Critical Care, 18, 200-209. http://dx.doi.org/10.4037/ajcc2009252

[2] Ministry of Health, Labour and Welfare Minister's Secretariat Statistics and Information Department (2005) Department of Demographics and Health Statistics, Health Statistics Room Medical Facility (Static and Dynamic) Survey, Hospital Fact Sheets 2005. http://www.mhlw.go.jp/toukei/saikin/hw/iryosd/05/index.html

[3] Ministry of Health, Labour and Welfare Minister’s Secretariat Statistics and Information Department (2011) Department of Demographics and Health Statistics, Health Statistics Room Medical Facility (Static and Dynamic) Survey, Hospital Fact Sheets. http://www.mhlw.go.jp/toukei/saikin/hw/iryosd/11/dl/sanko1.pdf

[4] Azoulay, E., Pochard, F., Chevret, S., Adrie, C., Annane, D., Bleichner, G., Bornstain, C., Bouffard, Y., Cohen, Y., Feissel, M., Goldgran-Toledano, D., Guitton, C., Hayon, J., Iglesias, E., Joly, L.M., Jourdain, M., Laplace, C., Lebert, C., Pingat, J., Poisson, C., Renault, A., Sanchez, O., Selcer, D., Timsit, J.F., Le Gall, J.R. and Schlemmer, B (2004) Half the Family Members of Intensive Care Unit Patients Do Not Want to Share in the Decision-Making Process: A Study in 78 French Intensive Care Units. Critical Care Medicine, 32, 1832-1838. http://dx.doi.org/10.1097/01.CCM.0000139693.88931.59

[5] White, D.B., Engelberg, R.A., Wenrich, M.D., Lo, B. and Curtis, J.R. (2007) Prognostication during Physician-Family Discussions about Limiting Life Support in Intensive Care Units. Critical Care Medicine, 35, 442-448. http://dx.doi.org/10.1097/01.CCM.0000254723.28270.14

[6] Pochard, F., Darmon, M., Fassier, T., Bollaert, P.E., Cheval, C., Coloigner, M., Merouani, A., Moulront, S., Pigne, E., Pingat, J., Zahar, J.R., Schlemmer, B. and Azoulay, E., French FAMIREA Study Group (2005) Symptoms of Anxiety and Depression in Family Members of Intensive Care Unit Patients before Discharge or Death. A Prospective Multicenter Study. Journal of Critical Care, 20, 90-96. http://dx.doi.org/10.1016/j.jcrc.2004.11.004

[7] Harvey, A.G. and Bryant, R.A. (1999) Dissociative Symptoms in Acute Stress Disorder. Journal of Traumatic Stress, 12, 673-680. http://dx.doi.org/10.1023/A:1024773202939

[8] Koopman, C., Classen, C., Cardena, E. and Spiegel, D. (1995) When Disaster Strikes. Acute Stress Disorder May Follow. Journal of Traumatic Stress, 8, 29-46. http://dx.doi.org/10.1002/jts.2490080103

[9] Fumls, R.R.L., Ranzani, O.T., Martins, P.S. and Schettino, G. (2015) Emotional Disorders in Pairs of Patients and Their Family Members during and after ICU Stay. PLOS ONE, 10, Article ID: e0115332.

[10] Sundararajan, K., Martin, M., Rajagopala, S. and Chapman, M.J. (2014) Posttraumatic Stress Disorder in Close Relatives of Intensive Care Unit Patients' Evaluation (PRICE) Study. Australian Critical Care, 27, 183-187. http://dx.doi.org/10.1016/j.aucc.2014.04.003

[11] McAdam, J.L., Fontaine, D.K., White, D.B., Dracup, K.A. and Puntillo, K.A. (2012) Psychological Symptoms of Family Members of High-Risk Intensive Care Unit Patients. American Journal of Critical Care, 21, 386-394. http://dx.doi.org/10.4037/ajcc2012582

[12] Gries, C.J., Engelberg, R.A., Kross, E.K., Zatzick, D., Nielsen, E.L., Downey, L. and Curtis, J.R. (2010) Predictors of Symptoms of Posttraumatic Stress and Depression in Family Members after Patient Death in the ICU. Chest, 137, 280-287. http://dx.doi.org/10.1378/chest.09-1291

[13] Chui, W.Y.Y. and Chan, S.W. (2007) Stress and Coping of Hong Kong Chinese Family Members during a Critical Ill- 
ness. Journal of Clinical Nursing, 16, 372-381. http://dx.doi.org/10.1111/j.1365-2702.2005.01461.x

[14] Leske, J.S. (1992) The Impact of Critical Injury as Described by a Spouse: A Retrospective Care Study. Clinical Nursing Research, 1, 385-401. http://dx.doi.org/10.1177/105477389200100407

[15] Miyamoto, C. and Hirose, Y. (2006) Feelings of Mothers with Infants Undergoing Cardiac Surgery: In the Case of Mothers Who Cared Their Children at Home before Surgery [in Japanese]. Journal of Japanese Society of Child Health Nursing, 15, 9-16.

[16] Fujimoto, R., Kuga, C., Koga, Y., Yamazaki, N., Yamashita, M., Tachino, J. and Yamase, H. (2010) Experience in Families of ICU Admitted Patients Who Have Cardiac Surgery [in Japanese]. Japan Journal of Nursing: Adult Health Nursing I, 40, 47-49.

[17] Salgado, C.L., Lamy, Z.C., de Abreu Haickel Nina, R.V., de Melo, L.A. and da Silva Nina, V.J. (2011) Pediatric Cardiac Surgery under the Parents Sight: A Qualitative Study. Revista Brasileira de Cirurgia Cardiovascular, 26, 36-42. http://dx.doi.org/10.1590/S0102-76382011000100009

[18] Breiwn, C.R., Anddrews, B. and Valentine, J.D. (2000) Meta-Analysis of Risk Factors for Posttraumatic Stress Disorder in Trauma-Exposed Adults. Journal of Consulting and Clinical Psychology, 68, 748-766. http://dx.doi.org/10.1037/0022-006X.68.5.748

[19] Van Horn, E. and Tesh, A. (2000) The Effect of Critical Care Hospitalization on Family Members: Stress and Response. Dimensions of Critical Care Nursing, 19, 40-49. http://dx.doi.org/10.1097/00003465-200019040-00014

[20] Ozer, E.J., Best, S.R., Lipsey, T.L. and Weiss, D.S. (2003) Predictors of Posttraumatic Stress Disorder and Symptoms in Adults: A Meta-Analysis. Psychological Bulletin, 129, 52-73. http://dx.doi.org/10.1037/0033-2909.129.1.52

[21] Mitchell, M.L. and Courtney, M. (2004) Reducing Family Members’ Anxiety and Uncertainty in Illness around Transfer from Intensive Care: An Intervention Study. Intensive and Critical Care Nursing, 20, 223-231.

http://dx.doi.org/10.1016/j.iccn.2004.05.008

[22] Lautrette, A., Darmon, M., Megarbane, B., Joly, L.M., Chevret, S., Adrie, C., Barnoud, D., Bleichner, G., Bruel, C., Choukroun, G., Curtis, J.R., Fieux, F., Galliot, R., Garrouste-Orgeas, M., Georges, H., Goldgran-Toledano, D., Jourdain, M., Loubert, G., Reignier, J., Saidi, F., Souweine, B., Vincent, F., Barnes, N.K., Pochard, F., Schlemmer, B. and Azoulay, E. (2007) A Communication Strategy and Brochure for Relatives of Patients Dying in the ICU. New England Journal of Medicine, 356, 469-478. http://dx.doi.org/10.1056/NEJMoa063446

[23] Paparrigopoulos, T., Melissaki, A., Efthymiou, A., Tsekou, H., Vadala, C., Kribeni, G., Pavlou, E. and Soldatos, C. (2006) Short-Term Psychological Impact on Family Members of Intensive Care Unit Patients. Journal of Psychosomatic Research, 61, 719-722. http://dx.doi.org/10.1016/j.jpsychores.2006.05.013

[24] Asukai, N., Hirohata, S., Kato, H. and Konishi, T. (2003) Psychometric Properties of the Japanese-Language Version of the Clinician-Administered PTSD Scale for DSM-IV [in Japanese with English Abstract]. Japanese Journal of Traumatic Stress, 1, 47-53.

[25] Knaus, W.A., Draper, E.A., Wagner, D.P. and Zimmerman, J.E. (1985) APACHE II: A Severity of Disease Classification System. Critical Care Medicine, 13, 818-829. http://dx.doi.org/10.1097/00003246-198510000-00009

[26] Asukai, N., Kato, H., Kawamura, N., Kim, Y., Yamamoto, K., Kishimoto, J., Miyake, Y. and Nishizono-Maher, A. (2002) Reliability and Validity of the Japanese-Language Version of the Impact of Event Scale-Revised (IES-R-J): Four Studies of Different Traumatic Events. Journal of Nervous \& Mental Disease, 190, 175-182. http://dx.doi.org/10.1097/00005053-200203000-00006

[27] Weiss, D.S. (2004) The Impact of Event Scale-Revised. In: Assessing Psychological Trauma and PTSD, 2nd Edition, The Guilford Press, New York, 168-189.

[28] American Psychiatric Association (2003) Diagnostic and Statistical Manual of Mental Disorders. 4th Edition, Text Revision, American Psychiatric Association, Washington DC.

[29] Sarason, I.G., Levine, H.M., Basham, R.B. and Sarason, B.R. (1983) Assessing Social Support: The Social Support Questionnaire. Journal of Personality and Social Psychology, 44, 127-139. http://dx.doi.org/10.1037/0022-3514.44.1.127

[30] Furukawa, T.A., Harai, H., Hirai, T., Kitamura, T. and Takahashi, K. (1999) Social Support Questionnaire among Psychiatric Patients with Various Diagnoses and Normal Controls. Social Psychiatry and Psychiatric Epidemiology, 34, 216-222. http://dx.doi.org/10.1007/s001270050136

[31] Armitage, P., Berry, G. and Matthew, J.N.S. (2002) Statistical Methods in Medical Research. 4th Edition, Blackwell, Oxford. http://dx.doi.org/10.1002/9780470773666

[32] Balluffi, A., Kassam-Adams, N., Kazak, A., Tucker, M., Dominguez, T. and Helfaer, M. (2004) Traumatic Stress in Parents of Children Admitted to the Pediatric Intensive Care Unit. Pediatric Critical Care Medicine, 5, 547-553. http://dx.doi.org/10.1097/01.PCC.0000137354.19807.44 
[33] Halm, M.A., Titler, M.G., Kleiber, C., Johnson, S.K., Montgomery, L.A., Craff, M.J., Buckwalter, K., Nicholson, A. and Megivern, K. (1993) Behavioral Responses of Family Members during Critical Illness. Clinical Nursing Research, 2, 414-437. http://dx.doi.org/10.1177/105477389300200405

[34] Cobb, S. (1976) Social Support as a Moderator of Life Stress. Psychosomatic Medicine, 38, 300-314. http://dx.doi.org/10.1097/00006842-197609000-00003

[35] Munakata, T. (1995) The Stress Release [in Japanese]. Shogakukan Library, Tokyo.

[36] Nakai, A., Fakazawa, M., Nagawa, M. and Kohata, F. (2011) Study of How Social Resources Are Used by Mothers of Physically Disabled Children [in Japanese]. Journal of Child Health, 70, 676-682.

[37] American Psychiatric Association (2013) Diagnostic and Statistical Manual of Mental Disorders. 5th Edition, Text Revision, American Psychiatric Association, Arlington. 